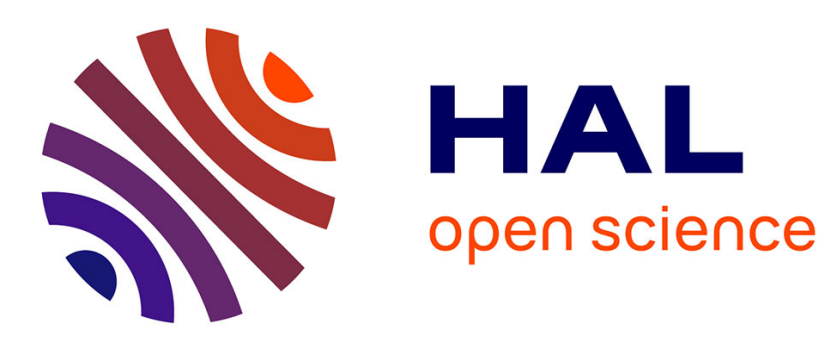

\title{
MgH2/PEG initiating system for ring opening polymerization of lactone and lactide
}

Nadia Guerrouani, André Mas, François Schué

\section{To cite this version:}

Nadia Guerrouani, André Mas, François Schué. MgH2/PEG initiating system for ring opening polymerization of lactone and lactide. e-polymers, 2010, 24, no pp given. 10.1515/epoly.2010.10.1.224 . hal-00476486

\section{HAL Id: hal-00476486 \\ https://hal.science/hal-00476486}

Submitted on 26 Apr 2010

HAL is a multi-disciplinary open access archive for the deposit and dissemination of scientific research documents, whether they are published or not. The documents may come from teaching and research institutions in France or abroad, or from public or private research centers.
L'archive ouverte pluridisciplinaire HAL, est destinée au dépôt et à la diffusion de documents scientifiques de niveau recherche, publiés ou non, émanant des établissements d'enseignement et de recherche français ou étrangers, des laboratoires publics ou privés. 


\title{
$\mathrm{MgH}_{2} / \mathrm{PEG}$ initiating system for ring opening polymerization of lactone and lactide
}

Nadia Guerrouani, André Mas ${ }^{*}$, François Schué

UMR 5253 CNRS-UM2-ENSCM-UM1, Institut Charles Gerhardt Montpellier, Equipe

IAM/SOM, Place Eugène Bataillon, 34095 Montpellier Cedex 5, France

Fax : 33-(0)467144028 ; E-mail : Andre.Mas02@univ-montp2.fr

Date of submission: 16 September, 2008

\begin{abstract}
Dihydroxy-terminated poly(ethylene glycol) and $\mathrm{MgH}_{2}$ form an efficient initiating system for the ring opening polymerization of $\varepsilon$-caprolactone and $\mathrm{L}$ lactide. Polycaprolactone-block-polyethylene glycol-block-polycaprolactone and polylactide-block-polyethylene glycol-block-polylactide were synthesized in bulk at $120^{\circ} \mathrm{C}$ for $16 \mathrm{~h}$ under argon. $\mathrm{MgH}_{2}$ provided a faster polymerization rate compared with other initiating systems based on non toxic metals used under vacuum.

Molecular weight of copolymers varied according to the monomer / ethylene oxide units ratio. The developed procedure led to easy polymerization with better control of the design, molecular weight and polydispersity of the final material. Copolymers were characterized by SEC, DSC, ${ }^{1} \mathrm{H}$ and ${ }^{13} \mathrm{C}$ NMR and IR. Micelles in aqueous solutions were prepared by finding balance between hydrophobic polyester and hydrophilic polyethylene glycol blocks.

Interest for this method is the use of $\mathrm{MgH}_{2}$ environmental chemical, absence of solvent and vacuum techniques, the possible recovery of solid material without further operation.
\end{abstract}

Keywords : block polymer; poly( $\varepsilon$-caprolactone); polylactide; poly(ethylene glycol). 


\section{Introduction}

Aliphatic polyesters from lactone or lactide and their copolymers have attracted much interest as non toxic biodegradable polymers over the past years. Many publications and patents deal with related syntheses in wide range of applications [1-7].

Polylactide (PLA), hydrolysable polyester known and used for a long time for medical applications, is one of the polymers widely accepted to play a major role as future packaging material, textiles and agriculture films [8]. This is mainly due to the good mechanical properties of PLA, which are comparable to today's standard packaging polymer, i.e. polystyrene [9-10]. PLA provides a closed natural cycle, being produced from plants and crops, polymerized and processed into packaging product and degraded after use into soil and humus.

Recently, polymeric micelles derived from copolymers of polylactide or $\operatorname{poly}(\varepsilon-$ caprolactone) (PCL) and polyethylene glycol (PEG) have attracted attention because of their bioresorbability, improved biocompatibility and potential application in drug delivery $[11,13]$. Polyesters based on lactic and glycolic acids (PLA/GA) are the most investigated and advanced bioresorbable polymers. They now cover an extensive range of applications such as surgical sutures. Moreover, nanocomposites based on such polyesters attracted interest due to possible upgrading of biocompatibility and biodegradability with a large range of polymers [14].

Ring opening polymerization of lactone and lactide, for which various effective systems have been developed [15], provided a direct and easy access to the corresponding high molecular weight polyesters. Many catalysts have been used for ring opening polymerization, the most widely used catalysts are tin compounds. Particularly important is tin (II) ethylhexanoate $\left(\mathrm{SnOct}_{2}\right)$ because of both its efficiency and possible use as a food additive [6,7,16-18]. SnOct 2 like most other tin compounds possesses a high cytotoxicity against a broad variety of microorganisms and thus it is used as food stabilizer as well as antifouling additive in paints. However, this cytotoxicity is undesirable when SnOct $_{2}$ or other tin salts are present as impurities in polymers [19].

It is highly recommended to use non toxic catalysts in the synthesis of polymers intended for biomedical, pharmaceutical and agriculture applications since complete removal of catalyst residues from the polymer is often impossible. This situation has prompted several research groups to explore the usefulness of initiators based on rather non toxic metals, such as $\mathrm{Fe}$ [20-22], $\mathrm{Zn}$ [23-39], $\mathrm{K}$ [40], $\mathrm{Ca}, \mathrm{Mg}$ and $\mathrm{Bi}$ [4,40- 
51]. Calcium based catalysts may serve this purpose and are gaining lots of interest. However, calcium compounds, such as calcium oxide, carbonate and carboxylate have low catalytic activity towards ring opening polymerization in bulk and require temperatures up to $180^{\circ} \mathrm{C}[52,53]$.

Polyglycolide homopolymers with high molecular weights and random copolymers of glycolyde and $\varepsilon$-caprolactone were synthesized using calcium acetylacetonate as a catalyst but the molecular weight could not be controlled and the end groups were not identified [54]. Calcium catalyst developed by Union Carbide has long been used for the heterogeneous ring opening polymerization of oxiranes. The structure of the catalyst however is still unclear, owing to the poor solubility and the high reactivity towards most organic solvents [55].

Calcium ammoniate catalyst for the ring opening polymerization of olefin oxides appeared in early 1960s and it was modified in 1980s. It was also effective in the polymerization of $\varepsilon$-caprolactone $(\mathrm{CL})$ and L-lactide $(\mathrm{LA})$ but its catalytic mechanism has not been clear yet because calcium ammoniate cannot dissolve in any organic solvents and it is very unstable and sensitive to moisture.

The synthesis of PLA-b-PEG-b-PLA triblock copolymers using $\mathrm{CaH}_{2}$ and $\mathrm{Zn}$ has been reported $[56,57]$. Although the residues were non toxic, the catalytic activity of such chemicals for ring opening polymerization was limited as evidenced by the high polymerisation temperature (140-150 $\left.{ }^{\circ} \mathrm{C}\right)$ and long polymerization time (4-5 days). Moreover, the whole process is carried out under vacuum. These disadvantages make an industrial development of the synthesis technologically more difficult and less profitable.

Therefore, in this paper, an efficient magnesium alkoxide initiating system generated in situ under argon or nitrogen from magnesium hydride $\left(\mathrm{MgH}_{2}\right)$ and dihydroxyterminated poly(ethylene glycol) has been developed. This new initiating system allowed us to synthesize PEG-based biodegradable triblock copolymers more rapidly than the similar systems based on Ca, Fe or Zn. PCL-b-PEG-b-PCL and PLA-b-PEG$b$-PLA were characterized by NMR, SEC and DSC. Amphiphilic properties were also evaluated by the measure of the wettability and surface energy of cast film and by the determination of the critical micelle concentration of aqueous solutions. 


\section{Results and discussion}

To demonstrate the efficiency of $\mathrm{MgH}_{2}$ for preparing a magnesium alkoxide initiating system for ring opening polymerization, the reaction was carried out in presence of dihydroxy-terminated $\mathrm{PEG}$ and $\mathrm{MgH}_{2}$ with various monomer / ethylene oxide units ratio ( $C L / E O$ and $L A / E O)$ under rigorously anhydrous conditions and solvent free. PCL- $b$-PEG- $b$-PCL and PLA- $b$-PEG- $b$-PLA triblock copolymers were obtained.

\section{Synthesis and triblock structure of PCL-b-PEG-b-PCL}

Conversion degree of $C L$ and structure of copolymers from NMR analyses

The kinetic of polymerization was followed by ${ }^{1} \mathrm{H}$ NMR and it was based on the disappearance of the monomer. This analysis made also possible to reach the molecular weight from the intensity of signals of protons attached to PCL blocks.

As a representative example for PEG 2000 (Figure 1), the intensity of the monomer peaks decreased in the course of polymerization indicating the consumption of $\mathrm{CL}$ monomer.

The comparison of intensity of $\mathrm{CH}$ signals of $\mathrm{CL}$ monomer at $4.25 \mathrm{ppm}$ and $\mathrm{CH}$ signals of PCL blocks at $4.04 \mathrm{ppm}$ led to the determination of the conversion degree. Complete conversion of monomer and $90 \%$ yield were obtained for $16 \mathrm{~h}$ reaction time under argon. The use of $\mathrm{MgH}_{2}$ provided a faster polymerization rate compared with $\mathrm{CaH}_{2}$ under vacuum reported by $\mathrm{Li}$ and al [57]. So, all polymerizations were carried out with the most suitable reaction conditions following: in bulk at $120^{\circ} \mathrm{C}$, in a glove box under dry argon atmosphere for $16 \mathrm{~h}$ (Table 1).

The polymerization was stopped by bring back product at room temperature, dissolution in chloroform, precipitation in methanol and drying under vacuum. Increasing the monomer concentration resulted in an increase in the molecular weight of copolymers. All copolymers exhibited CL/EO ratio close to the corresponding feed compositions.

A typical ${ }^{1} \mathrm{H}$ NMR spectrum of PCL- $b$-PEG- $b$-PCL (from PEG 2000, Mn $=12000 \mathrm{~g}$ $\mathrm{mol}^{-1}$ ) as well as the detailed assignment of the different peaks is shown in Figure 1. The peaks at 1.30, 1.55, 2.25 and $4.04 \mathrm{ppm}$ were assigned to the methylene proton atoms of PCL units and peak at 3.60 ppm was attributed to the methylene carbon atoms $\left(\mathrm{O}-\mathrm{CH}_{2}-\mathrm{CH}_{2}-\right)$ of PEG block.

The number molecular weight of triblock copolymer was calculated from the area ratio of the ${ }^{1} \mathrm{H}$ NMR peaks by equation (1). 
$M_{n \text { NMR }}=M_{n \text { PEG }}+\left(M_{n \text { PEG }} / 44 \times 114 \times 2 \times I_{C H 2(C L)} / I_{C H 2(P E G)}\right.$ 


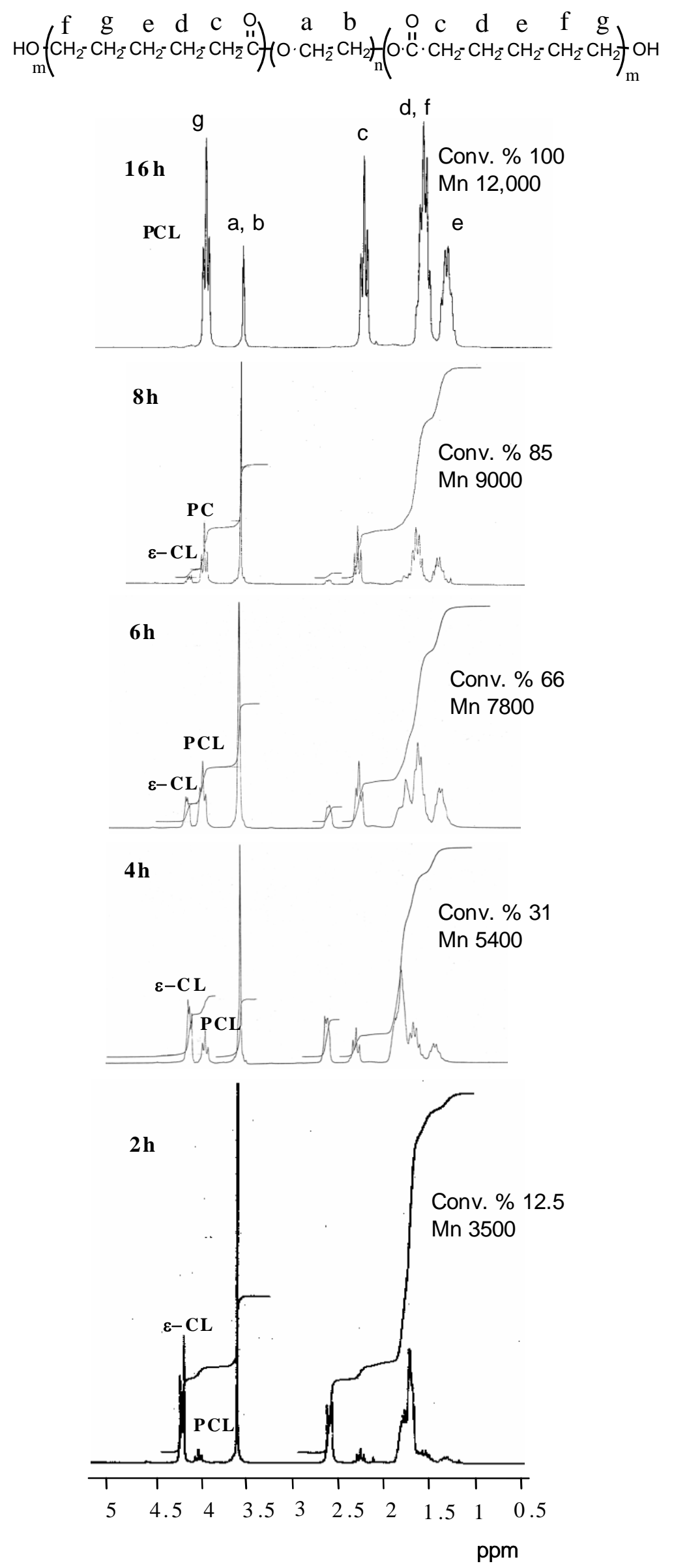


Fig. 1. ${ }^{1} \mathrm{H}$ NMR spectrum of PCL-b-PEG- $b$-PCL. Kinetic of polymerization from 2 to $16 \mathrm{~h}$ at $120^{\circ} \mathrm{C}$ under argon, conversion degree (conv. deg.) and number molecular weight $\left(M_{n}\right)$ of copolymer (PEG molecular weight $2000 \mathrm{~g} \mathrm{~mol}^{-1}$ ).

Tab. 1. Molecular weights, compositions and $T_{g}$ and $T_{m}$ of PCL-b-PEG-b-PCL triblock copolymers synthesized under argon at $120^{\circ} \mathrm{C}$ for $16 \mathrm{~h}$ with $\mathrm{MgH}_{2}$ as catalyst.

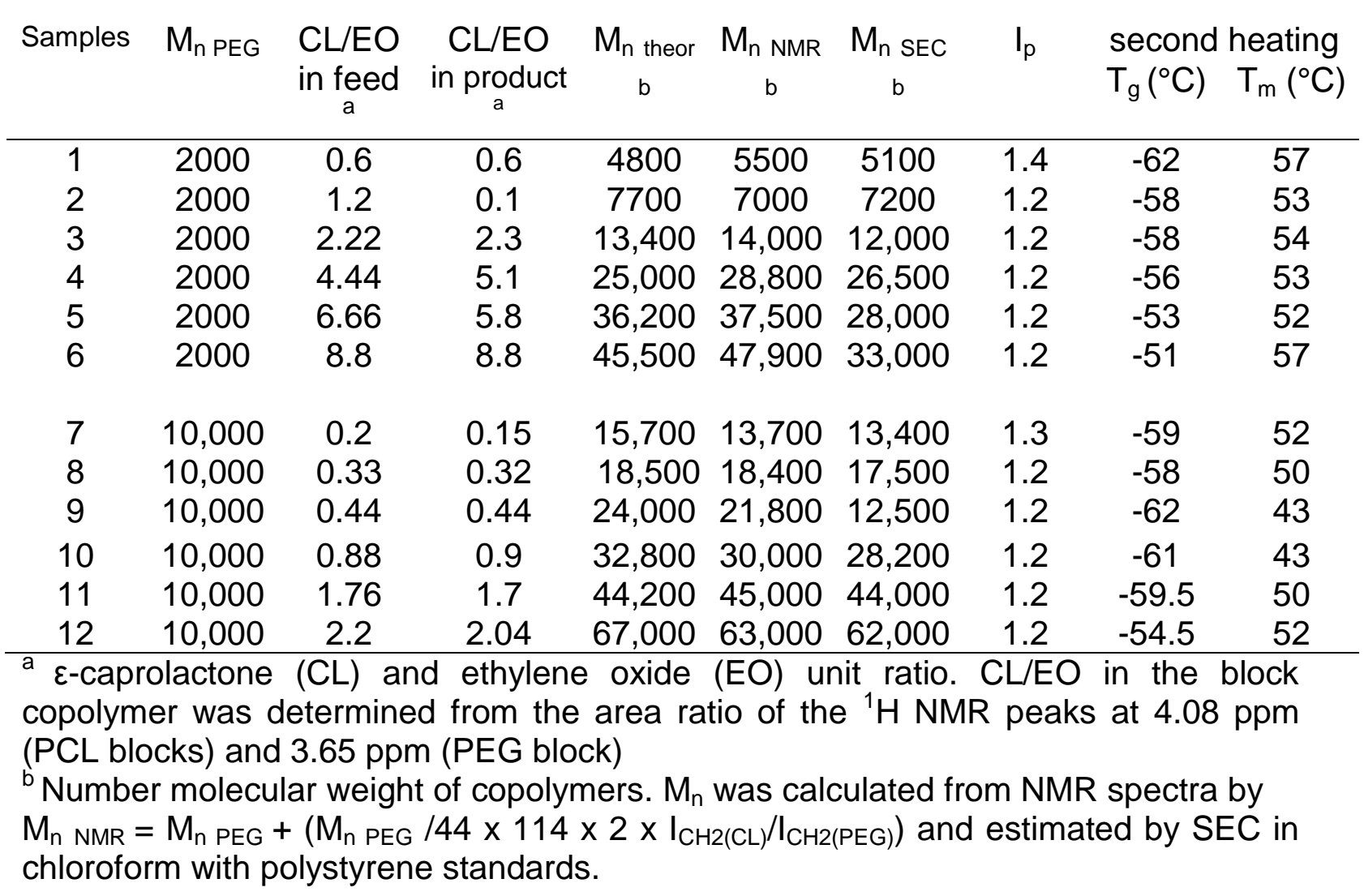

${ }^{13} \mathrm{C}$ NMR spectrum (Figure 2) showed the carbonyl region of the PCL blocks around $173 \mathrm{ppm}$, the methylene carbon atoms of PCL units at 64.0, 33.9, 28.2, 25.4, $24.4 \mathrm{ppm}$ and the methylene carbon atoms $\left(-\mathrm{O}-\mathrm{CH}_{2}-\mathrm{CH}_{2}-\right)$ at $70.4 \mathrm{ppm}$.

Two additional weak peaks at 69.1 and $32.2 \mathrm{ppm}$ were attributed to the linkage groups of block copolymer: the methylene carbon atom of the PEG block that is bonded directly to the PCL block via an ester linkage at $69.1 \mathrm{ppm}$ and the methylene carbon atom of the PCL block adjacent to the PEG block at $32.2 \mathrm{ppm}$.

${ }^{1} \mathrm{H}$ NMR and ${ }^{13} \mathrm{C}$ NMR spectra confirmed the PCL-b-PEG-b-PCL triblock structure of the copolymers. The central block came from the PEG used while the other two from the ring-opening polymerization of $\varepsilon$-caprolactone. The neighboring blocks were connected through an ester linkage. Therefore the PEG served as a macromolecular 
initiator for the polymerization of $\varepsilon$-caprolactone. Thus the above copolymerization can be depicted as in scheme 1 .

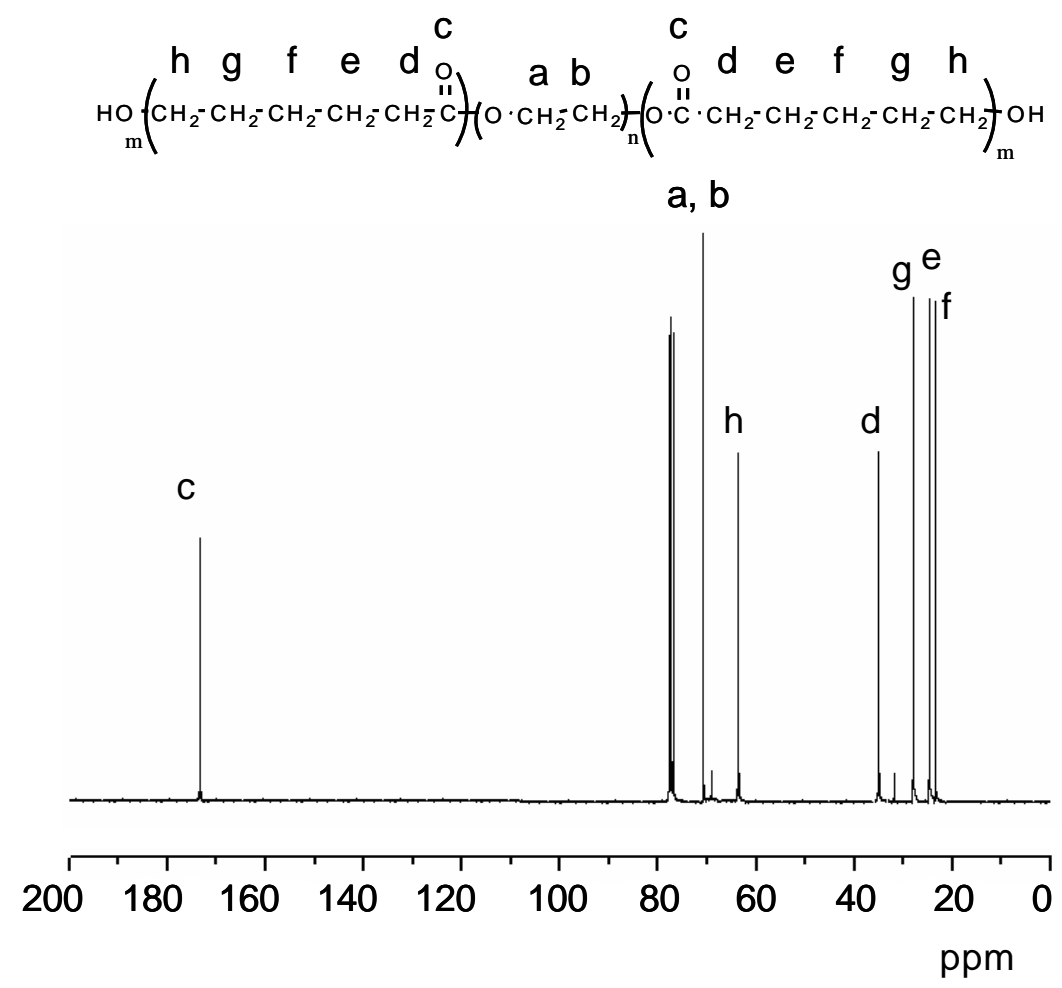

Fig. $2 .{ }^{13} \mathrm{C}$ NMR spectrum of PCL-b-PEG-b-PCL.

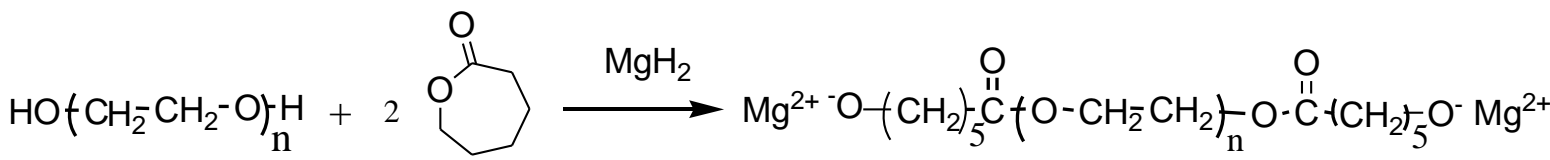

$$
\begin{aligned}
& 2+2(m-1) \stackrel{0}{11}
\end{aligned}
$$

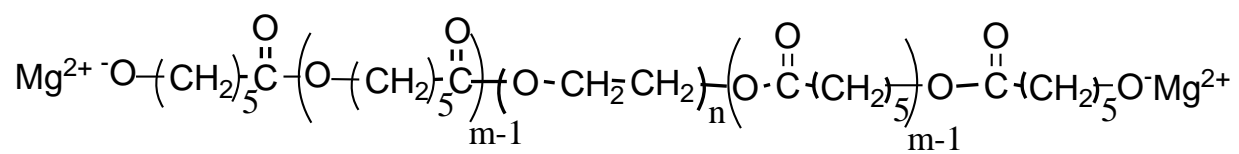

$$
\begin{aligned}
& \left.\left.\mathrm{H}-\left(\mathrm{O}-\left(\mathrm{CH}_{2}\right)_{5}^{\mathrm{O}} \mathrm{m}_{\mathrm{m}}^{\mathrm{O}}\right)_{\mathrm{O}} \mathrm{O}-\mathrm{CH}_{2} \mathrm{CH}_{2}\right)_{\mathrm{n}}\left(\mathrm{O}-\stackrel{\mathrm{O}}{\mathrm{O}}+\mathrm{CH}_{2}\right)_{5}\right)_{\mathrm{m}}^{+} \mathrm{OH}
\end{aligned}
$$

Scheme 1. Proposed mechanism for the formation of the PCL-b-PEG-b-PCL triblock copolymer. Mg divalent metal could lead to the possible formation of 2 initiating systems from 2 dihydroxy-terminated poly(ethylene glycol). Similar mechanism from 
HO-PEG-OH and lactide explains the formation of the PLA-b-PEG-b-PLA triblock copolymer.

It understood that the reaction of polymerization came to the stage of chain propagation. The $C L$ monomer was inserted into the magnesium alkoxide active centers to form the two PCL blocks. Therefore the two PCL blocks should be identical and they were generated by two active centers which have the same chemical activity. Finally, the propagation was terminated by hydrolysis of the active centers to form the $-\mathrm{OH}$ end groups.

\section{IR analysis}

IR spectra (not shown), of course, cannot be taken as evidence for the graft polymers structure but can confirm and reveal different characteristic functions of the copolymer obtained: ester bond vibration at $1727 \mathrm{~cm}^{-1}$ and $\mathrm{OH}$ vibration at 3683 , 3622 and $3455 \mathrm{~cm}^{-1}$ of $\mathrm{OH}$ end PCL, thus confirming the presence of both PCL and PEG units.

\section{SEC analysis}

SEC curves (not shown) of the block copolymers were unimodal and showed narrow molecular weight distribution, the molecular weight of PCL block linked to PEG followed a linear relationship with monomer conversion.

The data shown in Table 1 were used to calculate the predicted values of $M_{n}$ which were compared with those obtained by ${ }^{1} \mathrm{H}$ NMR and SEC. It should be noted the very close values observed between the theoretical and the experimental values. Values showed a relatively low polydispersity.

The value of $M_{n}$ depended on the $C L / E O$ ratio when the concentration of the catalyst was kept constant. An increase in the concentration of monomer, CL/EO ratio, led to an increase in $M_{n}$ of the copolymer as it has been shown by both NMR and SEC.

The molecular weight with a known molar ratio of the monomer to the catalyst determined by SEC was very close to the ones obtained by ${ }^{1} \mathrm{H} N M R$, within the expected experimental error.

Nevertheless, molecular weight of block copolymers determined by SEC using linear polystyrene standards in chloroform, was slightly smaller than the predicted value, it was particularly underestimated in the cases of samples 5, 6 and 9 in Table 1. Similar 
result was already reported for block copolymers based on PEG and PCL or poly( $\delta$ valerolactone) (PVL) [58]. In contrast, the molecular weight of PCL and PLA aliphatic polyesters determined by SEC with polystyrene calibration is typically overestimated, it is generally higher than the predicted value [59] because of a difference between polystyrene and aliphatic polyesters hydrodynamic volumes at the identical molecular weight. A better swelling of aliphatic polyesters in chloroform compared with copolyesters could be responsible for the variation in hydrodynamic volumes and the molecular weight determination. Perhaps, the presence of PEG hydrophilic block disturbs the extension of hydrophobic PCL chains in the same triblock or between neighbouring triblocks and limits the solvatation of PCL chain segments.

The suitable agreement between the calculated values of $M_{n}$ and those determined by NMR and SEC indicated that the HO-PEG-OH blocks were incorporated during the initiation step and that the polymerization proceeded exclusively by acyl-oxygen cleavage of $\varepsilon$-caprolactone. The molecular weight of copolymer increased proportionally with an increasing molar ratio of $C L$ to PEG. This implies, on one hand, that the ring opening polymerization of $\mathrm{CL}$ is driven from the hydroxy tail of HO-PEG$\mathrm{OH}$ and, on the other one, that HO-PEG-OH plays the role of the initiator for the ring opening polymerization of $\varepsilon$-caprolactone in presence of $\mathrm{MgH}_{2}$. The perfect control over molecular weight and low polydispersity indicated that the mechanism is a living polymerization nature.

\section{DSC and WAXD analyses}

PEG 2000 homopolymer showed glass transition temperature $\left(T_{g}=-62.3^{\circ} \mathrm{C}\right)$ and single melting peak $\left(T_{m}=58.2{ }^{\circ} \mathrm{C}\right)$ while the corresponding temperatures of PCL 20,000 were located at $\mathrm{T}_{\mathrm{g}}=-50.8{ }^{\circ} \mathrm{C}$ and $\mathrm{T}_{\mathrm{m}}=54.5^{\circ} \mathrm{C}$. We did not observe any crystallization peak for both polymers. We noticed that also both homopolymers had comparable glass transition and melting temperatures. The DSC curves of the PCL$b$-PEG-b-PCL triblock copolymers exhibited only two temperatures, $T_{g}$ varying from 62 to $-50^{\circ} \mathrm{C}$ and $T_{m}$ varying from $43{ }^{\circ} \mathrm{C}$ to $59.6^{\circ} \mathrm{C}$ with molecular weight (Table 1). The PCL blocks were comparably long with respect to the length of PEG block. Similar results were observed for PEG 10,000. Therefore it is difficult to conclude that phase separation takes place in these triblock copolymers to form interconnected PCL domain and PEG domain. 
While basing on the analyses carried out, we can consider that the melting peak of the copolymer corresponds to PCL blocks, and that PEG is in an amorphous state.

To consolidate these assertions, analyses of $X$-rays diffractions were carried out. WAXD spectra of PCL-b-PEG-b-PCL triblock copolymers, PEG and PCL homopolymers are shown in figure 3.

The crystalline pattern of PEG block was not observed in all triblock samples, WAXD measurement presented only two crystallization rays at $10.5^{\circ}$ and $11.9^{\circ}$ which are characteristic of the peaks of crystallization of PCL [60]. Thus we can conclude that only the PCL block is in a crystalline state in the copolymer and that the melting point recorded on the DSC thermogram corresponds to PCL block.

These results prove the presence of the separated microdomains in the triblock copolymers. The thermograms and diffractograms of various triblock copolymers are similar, thus confirming the phase separation for all the synthesized block copolymers. 

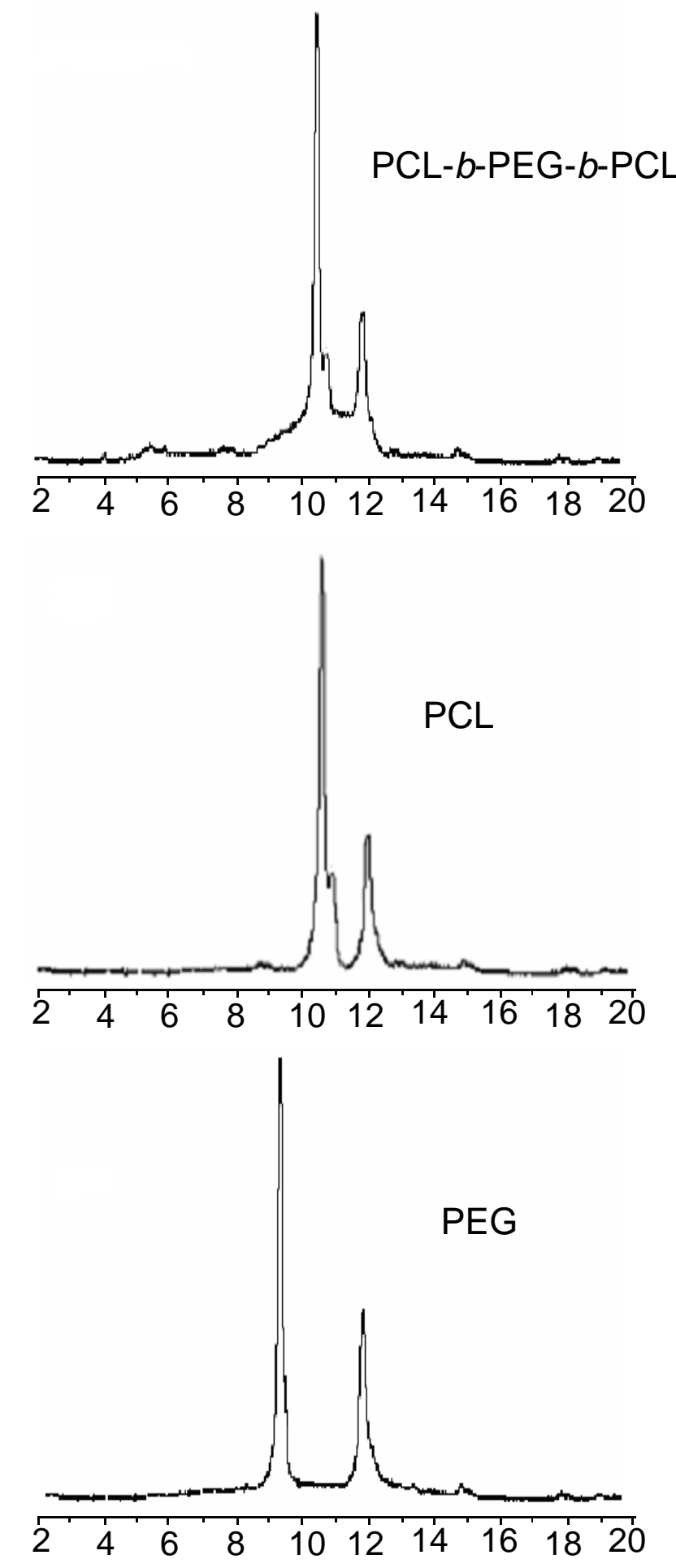

Theta (degree)

Fig. 3. X-ray diffraction patterns of PEG, PCL and PCL-b-PEG- $b$-PCL.

2. Synthesis and triblock structure of PLA-b-PEG-b-PLA 
Same procedure described above was used for the preparation of PLA- $b$-PEG- $b$-PLA triblock copolymers from L-lactide and dihydroxy-terminated PEG, Mn = 2000 and 10,000. Copolymers with different molecular weight were prepared by varying the initial L-lactide concentration with $\mathrm{MgH}_{2}$ kept constant. Results are reported in Table 2 .

Tab. 2. Molecular weights, compositions and $T_{g}$ and $T_{m}$ of PLA- $b$-PEG- $b$-PLA triblock copolymers synthesized under argon at $120^{\circ} \mathrm{C}$ for $16 \mathrm{~h}$ with $\mathrm{MgH}_{2}$ as catalyst.

\begin{tabular}{|c|c|c|c|c|c|c|c|c|c|}
\hline Samples & $\mathrm{M}_{\mathrm{n} \text { PEG }}$ & $\begin{array}{c}\text { LA/EO } \\
\text { in feed } \\
\text { a }\end{array}$ & $\begin{array}{c}\mathrm{LA} / \mathrm{EO} \\
\text { in product } \\
\mathrm{a}\end{array}$ & $\begin{array}{c}M_{n} \text { theor } \\
b\end{array}$ & $\underset{\mathrm{b}}{\mathrm{M}_{\mathrm{n} N \mathrm{~N}}}$ & $\begin{array}{c}M_{n} \text { SEC } \\
b\end{array}$ & $I_{p}$ & $\begin{array}{l}\text { second } \\
\mathrm{T}_{\mathrm{g}}\left({ }^{\circ} \mathrm{C}\right)\end{array}$ & $\begin{array}{l}\text { heating } \\
\mathrm{T}_{\mathrm{m}}\left({ }^{\circ} \mathrm{C}\right)\end{array}$ \\
\hline 1 & 2000 & 1.2 & 1.5 & 5600 & 7000 & 6100 & 1.2 & 0 & - \\
\hline 2 & 2000 & 2.3 & 2.4 & 9200 & 10,000 & 10,400 & 1.2 & 14 & - \\
\hline 3 & 2000 & 3.4 & 2.8 & 12,800 & 11,000 & 11,000 & 1.3 & 28 & 120 \\
\hline 4 & 2000 & 4.44 & 4.12 & 16,400 & 15,600 & 13,500 & 1.2 & 30 & 128 \\
\hline 5 & 2000 & 6.66 & 5.8 & 30,800 & 29,900 & 28,000 & 1.2 & 36 & 140 \\
\hline 6 & 2000 & 8.8 & 8.8 & 45,200 & 39,000 & 43,000 & 1.2 & 41 & 142 \\
\hline 7 & 10,000 & 0.4 & 0.3 & 17,200 & 14,800 & 13,200 & 1.3 & -35 & - \\
\hline 8 & 10,000 & 0.66 & 0.6 & 20,800 & 20,000 & 19,700 & 1.2 & -20 & - \\
\hline 9 & 10,000 & 0.88 & 0.9 & 25,000 & 25,000 & 28,200 & 1.2 & -10 & 100 \\
\hline 10 & 10,000 & 1.7 & 1.65 & 38,800 & 37,000 & 38,200 & 1.2 & -9 & 134 \\
\hline 11 & 10,000 & 2.6 & 2.3 & 53,000 & 48,000 & 49,000 & 1.2 & 17 & 136 \\
\hline 12 & 10,000 & 3.4 & 3.6 & 67,600 & 67,000 & 66,800 & 1.2 & 42 & 140 \\
\hline
\end{tabular}

${ }^{a}$ Lactide (LA) and ethylene oxide (EO) unit ratio. LA/EO in the block copolymer was determined from the area ratio of the ${ }^{1} \mathrm{H}$ NMR peaks at $1.45 \mathrm{ppm}$ (PLA block) and 3.65 ppm (PEG block)

${ }^{\mathrm{b}}$ Number molecular weight of copolymers. $\mathrm{M}_{\mathrm{n}}$ was calculated from NMR spectra by $M_{n N M R}=M_{n}$ PEG $+\left(M_{n}\right.$ PEG $\left./ 44 \times 72 \times 4 \times I_{C H 3(L A)} / I_{C H 2(P E G)}\right)$ and estimated by SEC in chloroform with polystyrene standards.

NMR analysis

As an illustrative example, ${ }^{1} \mathrm{H}$ NMR spectrum of a PLA- $b$-PEG- $b$-PLA triblock copolymer (sample 2 in Table 2) is shown in Figure 4.

The analysis allowed the characterization of the specific linkages due to the block copolymer architecture. The number molecular weight of copolymers was calculated from the ${ }^{1} \mathrm{H}$ NMR peaks by the equation (2).

$$
M_{n \text { NMR }}=M_{n \text { PEG }}+\left(M_{n} \text { PEG } / 44 \times 72 \times 4 \times I_{\text {CH3 (LA) }} / I_{C H 2 \text { (PEG) })}\right.
$$




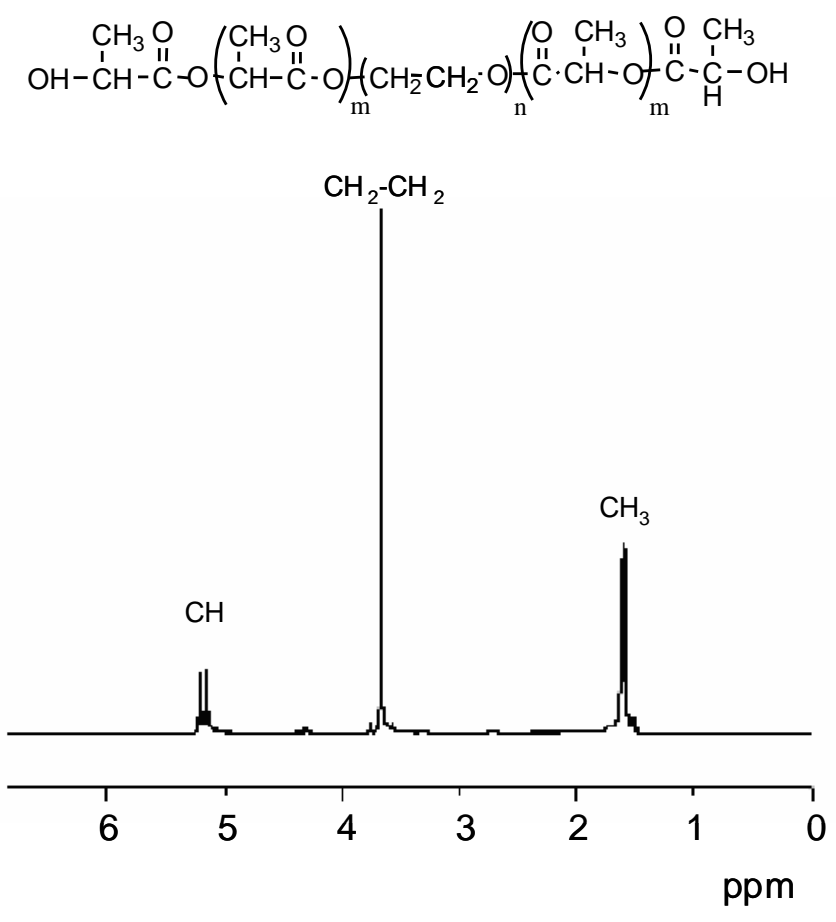

Fig. 4. ${ }^{1} \mathrm{H}$ NMR spectrum of PLA- $b-\mathrm{PEG}-b-\mathrm{PLA}$.

The multiplet around $4.3 \mathrm{ppm}$ is assigned to the methylene signal corresponding to the junction between PEG and PLA blocks (PLA-COO- $\left.\mathrm{CH}_{2}\right)$ [42].

The presence of this multiplet is indicative of PLA-PEG linkage. The peak at $3.7 \mathrm{ppm}$ was assigned to the methylene group of PEG block and peaks at 1.7 and 5.2 ppm to methyl and methine proton atoms of PLA block respectively. Thus the above copolymerization can be depicted as in scheme 1(with LA instead of CL).

${ }^{13} \mathrm{C}$ NMR spectrum of PLA-b-PEG-b-PLA (Figure 5) showed peaks at 169.3 and $174.30 \mathrm{ppm}$ attributed to the carbonyl group of the polyester blocks and peaks at 17.3 and 69.5 ppm attributed respectively to methyl and methine carbon atoms. First investigations based on ${ }^{13} \mathrm{C}$ NMR analysis also indicated that the stereochemistry of the chiral carbon atom of the L-lactide monomer $\mathrm{CO}-\underline{\mathrm{CH}}\left(\mathrm{CH}_{3}\right)-\mathrm{O}$ was unchanged during the polymerization leading to the formation of stereoregular sequence as $\mathrm{P}(\mathrm{L}$ LA). 

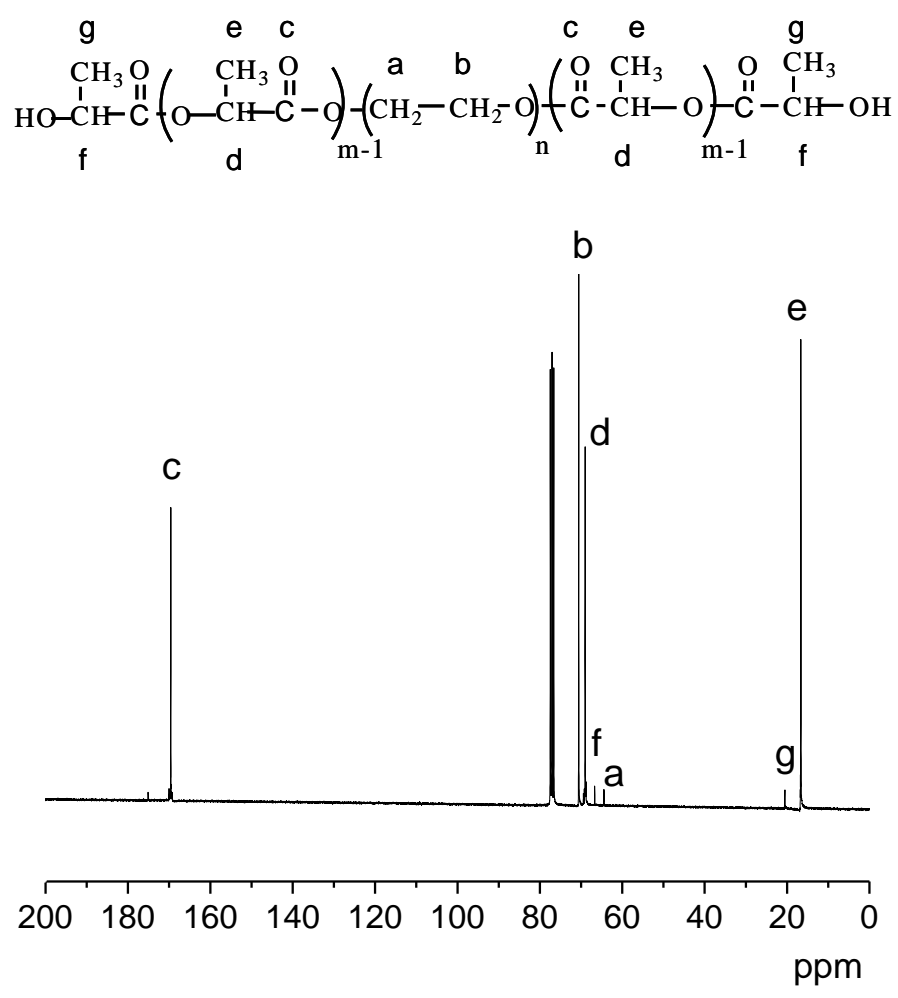

Fig. $5 .{ }^{13} \mathrm{C}$ NMR spectrum of PLA-b-PEG-b-PLA.

This means that no racemization happened during the polymerization, which would generate other sequences such as $\mathrm{P}(\mathrm{DL}-\mathrm{LA})$ or $\mathrm{P}(\mathrm{D}-\mathrm{LA})$. However detailed works are currently developed to specify the stereochemistry of PLA blocks under definite conditions.

\section{IR analysis}

IR spectrum (not shown) was similar to that of PCL-b-PEG-b-PCL. Ester bond vibration was situated at $1738 \mathrm{~cm}^{-1}$.

\section{SEC analysis}

SEC curves of block copolymers were unimodal with a narrow molecular weight distribution. Copolymers had relatively low polydispersity and the number molecular weights estimated by SEC were very close to the ones determined by ${ }^{1} \mathrm{H}$ NMR. All copolymers exhibited ratios of LA/EO close to the corresponding feed composition, 
moreover $M_{n}$ SEC and $M_{n}$ NMR were very close to the theoretical $M_{n}$ value (Table 2), $M_{n}$ SEC are slightly smaller than $M_{n}$ NMR as discussed for PCL-PEG-PCL triblock. The good agreement between experimental and calculated $M_{n}$ values indicated that the HO-PEG-OH block was incorporated to the triblock structure.

$\mathrm{M}_{n}$ depended on LA concentration when the concentrations of $P E G$ and $\mathrm{MgH}_{2}$ were kept constant. An increase in the concentration of monomer, led to an increase in $M_{n}$ of the block copolymer. Such results allowed to conclude that the polymerization presents a living character.

\section{DSC analysis}

PLA 20,000 homopolymer showed glass transition temperature at $T_{g}=46.6{ }^{\circ} \mathrm{C}$ and single melting point at $T_{m}=140{ }^{\circ} \mathrm{C}$. DSC curves of PLA- $b$-PEG- $b$-PLA triblock copolymers exhibited only two temperatures, $T_{g}$ varying from -35 to $43 \stackrel{\circ}{\circ} \mathrm{C}$ and $T_{m}$ varying from 100.1 to $134.1^{\circ} \mathrm{C}$ according to the composition of the copolymer and the length of PEG and PLA blocks (Table 2). In very few cases, a crystallisation temperature at about $91^{\circ} \mathrm{C}$ was detected.

The glass transition temperatures have also been calculated following the Fox equation (3)

$$
1 / T_{g}=\omega_{1} / T_{g 1}+\omega_{2} / T_{g 2}
$$

where $T_{g}$ is the glass transition temperature of the copolymer, $T_{g 1}=-62 .{ }^{\circ} \mathrm{C}$ is the glass transition temperature of PEG and $\mathrm{T}_{\mathrm{g} 2}=46.6 \stackrel{\circ}{\circ} \mathrm{C}$ for PLA; $\omega_{1}$ and $\omega_{2}$ are the weight fractions of EO units and LA units in the copolymer.

The calculated values indicated a disagreement with the experimental values determined by DSC. This seems to indicate that the copolymers may contain non compatible blocks, as we observed a $T_{g}$ between those of the corresponding pure homopolymers as well as non relationship between $T_{g}$ and weight fractions of PLA and PEG blocks.

WAXD spectra of PEG, PLLA homopolymers and PLA-b-PEG- $b$-PLA triblock copolymers are shown in figure 6 .

The crystalline pattern of PEG block was not observed in all samples, the spectra presented only two crystallization rays at $8.5^{\circ}$ and $9.7^{\circ}$ attributed to the crystallization of PLA. The intensity of rays was dependent on LA / EO ratio, it 
increased with the length of PLA blocks but the diffraction angle did not change, showing that PEG blocks are excluded from the crystallized PLA blocks.

These results confirm the presence of microdomains in triblock copolymers and non miscibility between PEG and PLA blocks.

\section{Micelles preparation and characterization}

The increase of hydrophilic nature of PCL and PLA by introducing PEG block to form copolymer would allow the formation of micelles in aqueous media [60-64]. The possibility of micelle formation depends on the hydrophilic/hydrophobic balance of copolymers which is characterized by the wettability, the surface energy and the critical micelle concentration (CMC).

Water contact angle $\left(\theta_{\mathrm{H} 2 \mathrm{O}}\right)$ of polymer films increased gradually according to the length of hydrophobic blocks. $\theta_{\mathrm{H} 2 \mathrm{O}}$ globally varied from about $15^{\circ}$ for PEG 2,000 and 10,000 to $84^{\circ}$ and $75^{\circ}$ for PCL- $b$-PEG- $b$-PCL and PLA- $b$-PEG- $b$-PLA films with same molecular weight about $70,000 \mathrm{~g} \mathrm{~mol}^{-1}$.

Consequently, the wettability and surface energy $\left(\gamma_{s}\right)$ gradually decreased, mainly due to the decrease of polar component $\left(\mathrm{Y}_{\mathrm{s}}^{\mathrm{p}}\right)$, from about $70 \mathrm{~mJ} \mathrm{~m}^{-2}$ to $42-46 \mathrm{~mJ} \mathrm{~m}^{-2}$ (Figure 7 as a representative graph). 

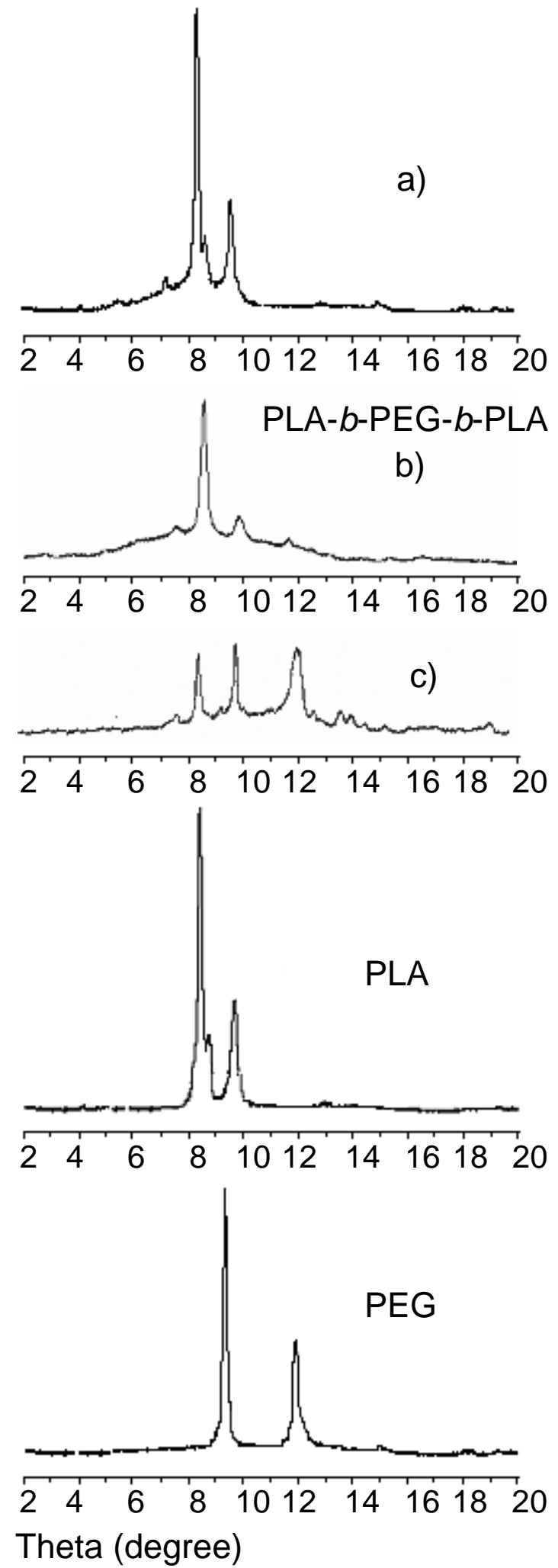

Fig. 6. X-ray diffraction pattern of PEG, PLLA and PLA-b-PEG-b-PLA. A), b), c) respectively sample 6, 4, 9 in Table 2 . 


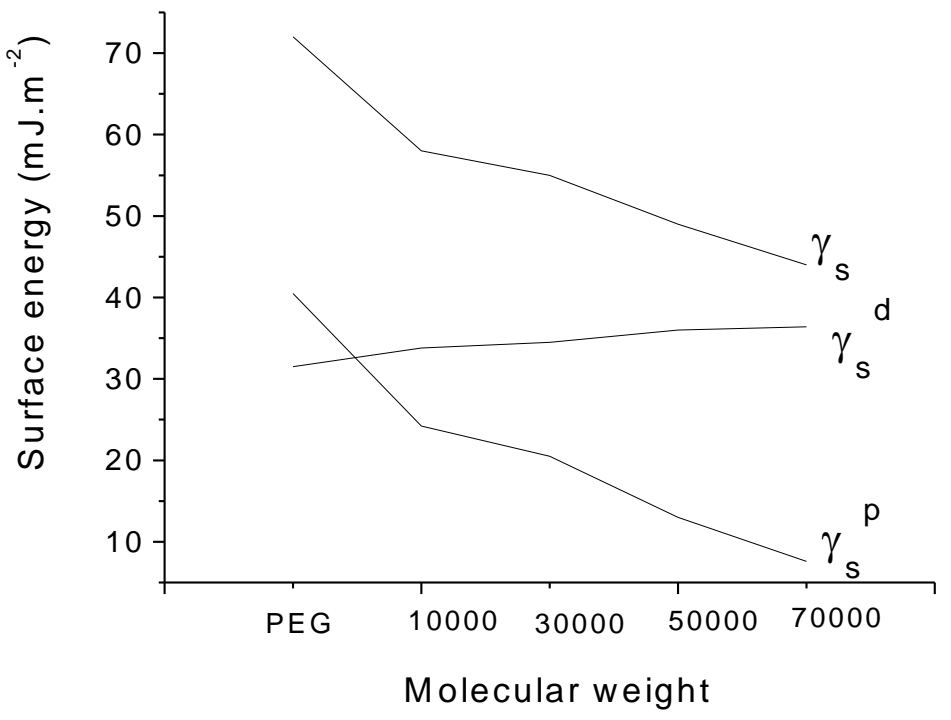

Fig. 7. Variation of the surface energy $\left(\gamma_{s}\right)$, polar $\left(\gamma_{s}{ }^{p}\right)$ and dispersive $\left(\gamma_{s}{ }^{d}\right)$ components of PLA-b-PEG- $b$-PLA film with the increase of PLA block length (PEG $2000 \mathrm{~g} \mathrm{~mol}^{-1}$ ). Similar graphs were obtained for PLA- $b$-PEG- $b$-PLA and PCL- $b$-PEGb-PCL with PEG $10,000 \mathrm{~g} \mathrm{~mol}^{-1}$.

The optimization of the formation of micelles is closely related to the research of best ratio between the number average polymerization degree of the central hydrophilic PEG block and that of the side hydrophobic PCL or PLA blocks. The hydrophobic blocks aggregate from the core and the hydrophilic blocks form the outer shell. Micelles were prepared via the addition of THF solution of copolymers in water. CMC was deduced from the graph of surface tension of aqueous solution of copolymers versus the polymer concentration. Surface tension decreased with increasing the concentration below CMC and it is nearly constant above CMC. CMC was then taken as the change in slope of the graph. CMC was in 0.2-0.9 $\mathrm{g} \mathrm{L}^{-1}$ range for PCL- $b$-PEG$b$-PCL and PLA-b-PEG-b-PLA aqueous solutions and it decreased according to the increase of length of hydrophobic blocks (Figure 8).

It is found that the diameter of the micelles indeed increased with the increase of the length of hydrophobic blocks, the number of micelles increased with the increase of concentration and these micelles are of unimodal size distribution. 


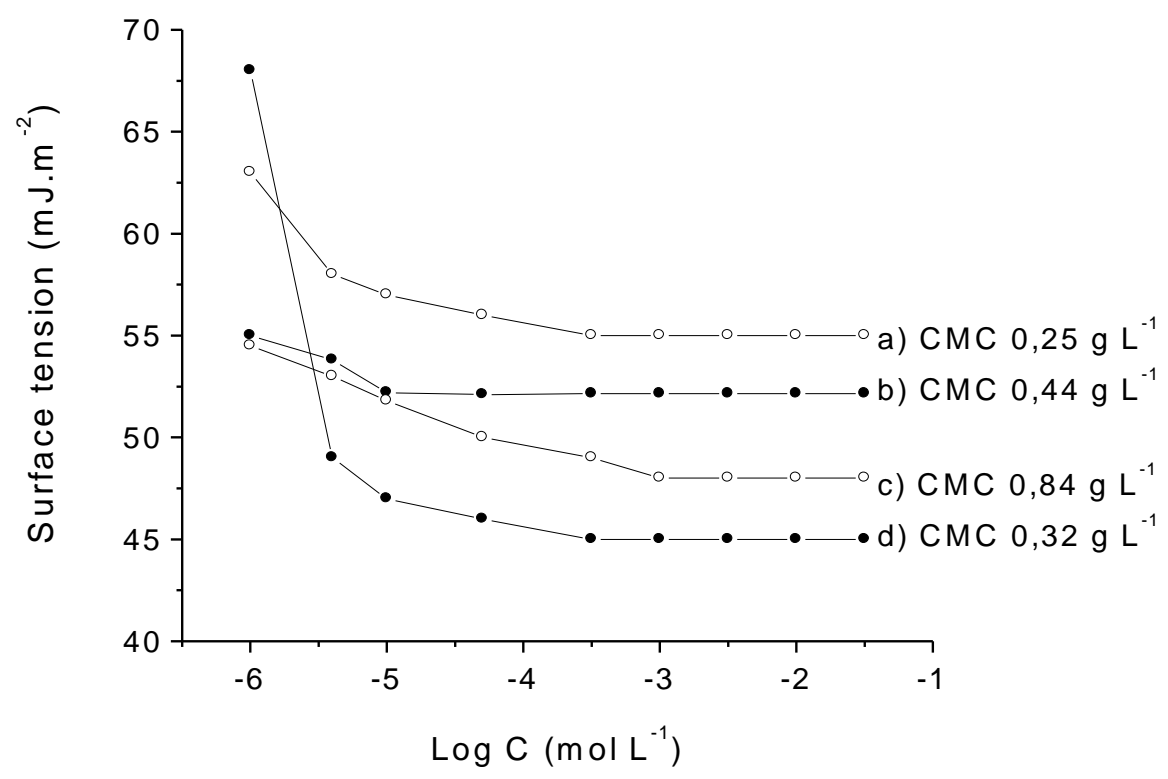

Fig. 8. Variation of the surface tension of aqueous solution of block copolymers with the concentration: PLA- $b-\mathrm{PEG}-b-\mathrm{PLA}\left(^{\circ}\right)$ a) $\mathrm{M}_{\mathrm{n}}=25000 \mathrm{~g} \mathrm{~mol}^{-1} \mathrm{c}$ ) $\mathrm{M}_{\mathrm{n}}=15000 \mathrm{~g} \mathrm{~mol}^{-1}$ and PCL-b-PEG-b-PCL (.) b) $M_{n}=14000 \mathrm{~g} \mathrm{~mol}^{-1}$ d) $M_{n}=18400 \mathrm{~g} \mathrm{~mol}^{-1}$.

\section{Conclusions}

$\mathrm{MgH}_{2}$ led to the formation of an alkoxide system with PEG that initiated the ring opening polymerization of $\varepsilon$-caprolactone and L-lactide. The formation of block copolymers between PEG and PCL or PLA was confirmed by several characterization techniques.

Copolymers PCL- $b$-PEG- $b$-PCL and PLA- $b$-PEG- $b$-PLA were synthesized in bulk under argon. Interest for this method is the use of an environmental system, absence of solvent and vacuum techniques, and possible recovery of solid material without further operation. The operative conditions and yield were better than those already reported; they are in favour of a possible development on a works scale.

The synthesis is efficient, easy to control and no transesterification reaction has been detected.

DSC results indicated that the variation in physical properties is adjusted by the variation in copolymer compositions; the copolymers obtained contain non compatible blocks, as we observe by WAXD analysis. 
The curves of distribution were unimodale with a narrow polydispersity around 1.2. The average molecular weight calculated by ${ }^{1} \mathrm{H}$ NMR and obtained by SEC is almost identical. The conversion products are about $100 \%$ and yields reach $90 \%$.

The developed procedure enables polymerization with better control of the design, molecular weight, and polydispersity of the final material.

The wettability study showed the variation in the hydrophobic nature of the copolymer while the polyester blocks increased. We succeeded to obtain micelles in aqueous solution by finding balance between hydrophobic polyester blocks and hydrophilic PEG block.

These synthesized biodegradable block copolymers are interesting as materials for biodegradable drug delivery systems, among others.

\section{Experimental part}

\section{Materials}

e-caprolactone ( $\mathrm{CL}$ ) (Sigma Aldrich) was purified by drying over $\mathrm{CaH}_{2}$, followed by a distillation under vacuum and finally stored under argon atmosphere. L-lactide (LA) (Sigma Aldrich) was purified by crystallization from dried toluene and sublimated. Dihydroxy-terminated poly(ethylene glycol) (PEG) with number average molecular weight 2000 and $10,000 \mathrm{~g} / \mathrm{mol}$ (Sigma Aldrich) were purified by dissolution in chloroform and precipitation in diethyl ether, followed by drying under high vacuum more than one week just before use. Chiral L-LA monomer was selected for investigation into the stereochemistry of the polymerization. Complete results will be published shortly. In this article, polylactide block is called PLA without reference to the possible stereoregularity of the polymer chain. Magnesium hydride $\left(\mathrm{MgH}_{2}\right)$ (Sigma Aldrich) was used as received. $\mathrm{X}$ rays analysis of $\mathrm{MgH}_{2}$ gave in at \%, after deducting oxygen from analysis under air: $\mathrm{Mg}$ 99.38, Ca 0.1, Al 0.38, Si 0.12, Fe 0.01 . Commercially available solvents were used as received without further purification.

\section{Synthesis of copolymers}

The systems modelled in this study are the ring opening polymerization of $C L$ and $L A$ with $\mathrm{MgH}_{2}$ and $\mathrm{PEG}$ as the initiating complex. PEG was used to represent both the initiating hydroxyl functionality and the propagation of polyester chain. 
As an illustrative example: in a glove box purged by dry argon, weighed amount of PEG, finely grinded $\mathrm{MgH}_{2}$ at a proportion of 0.069 mole of $\mathrm{MgH}_{2}$ per terminal hydroxyl of PEG and 6.9 mmole of CL or LA were introduced in a dry tube equipped with a magnetic stirrer. The tube was closed with a serum cap under argon and immersed in a silicon oil bath at $120^{\circ} \mathrm{C}$ for 16 hours. The copolymer thus obtained was purified by dissolution in chloroform and precipitation in methanol (two times). The solid product was dried under reduced pressure until constant weight was obtained.

\section{Characterization}

${ }^{1} \mathrm{H}$ NMR and ${ }^{13} \mathrm{C}$ NMR were recorded with a Bruker spectrometer, at 400 and 100 $\mathrm{MHz}$ respectively, in $\mathrm{CDCl}_{3}$ solution at $25^{\circ} \mathrm{C}$. Chemical shifts are given in ppm downfield from TMS. Differential Scanning Calorimetry (DSC) measurements were carried out on Metler DSC 30 instrument, in sealed aluminium pans under nitrogen atmosphere, at $10^{\circ} \mathrm{C} / \mathrm{min}$ heating rate, calibrated with indium standards. SEC analysis was conducted with a Waters 2410 apparatus equipped with Styragel HR3, HR4 and HR5 columns and analyzed with an RI detector (Waters 2410) with chloroform as eluent at a flow rate of $0.5 \mathrm{~mL} / \mathrm{min}$, using a Waters 515 pump at $35^{\circ} \mathrm{C}$. Molecular weights were calibrated with polystyrene standards. Wide-angle X-ray diffraction (WAXD) was performed using a Philips diffractometer with $\mathrm{Ni}$-filtered Cu Ka radiation.

\section{Wettability of copolymer films}

Wettability and surface energy were determined by contact angle measuring. Films were obtained from copolymer solutions in $\mathrm{CHCl}_{3}$ which were cast on a glass plate. After solvent evaporation, films were dried at $40^{\circ} \mathrm{C}$ for 4 hours. The contact angle measuring was made $5 \mathrm{~s}$ after the drop was deposited and the surface energy was calculated by the Owens and Wendt method using water and diiodomethane [65].

\section{Micelle preparation}

To prepare an aqueous solution, the copolymer solution in tetrahydrofuran (THF) with various concentrations, was added dropwise to doubly distilled water under stirring and then THF was removed using a rotary evaporator at $25^{\circ} \mathrm{C}$ for $2 \mathrm{~h}$. 


\section{References}

[1] Kafrawy, A.; Shalaby, S.W.; J. Polym. Sci. Part A: Polym. Chem. 1981, 25, 2629.

[2] Neujjenhuis, A.J.; Gripma, D.W.; Penning, A.J.; Macromolecules 1996, 29,1965.

[3] Rafler, G.; Dahlmann, J.; Acta. Polym. 1992, 43, 91.

[4] Leenslag, J.W.; Pennings, A.J.; Makromol. Chem. 1987, 188,1809.

[5] Du, Y.J.; Lemstra, P.J.; Nijenhuis, A.J.; Vanaert; H.A.M.; Bastiaansen, C.; Macromolecules 1995, 8, 2124.

[6] Duda, A.; Penczek, S.; Kowalski, A.; Libiszowski, J.; Macromol. Symp. 2000, 153, 41.

[7] Kowalski, A.; Duda, A.; Penczek, S.; Macromolecules 2000, 33, 689.

[8] Drumright, R.E.; Gruber, P.R.; Henton. D.E.; Adv. Mater. 2000, 12, 1841.

[9] Meinander, K.; Niemi, M.; Hakola, J.S.; Selin, J.F.; Macromol. Symp. (37th Microsymposium on Macromolecules (Bio)degradable Polymers) 1997, 123, 147.

[10] Sinclair, R.G.; J. Macromol. Sci. Part A: Pure Appl. Chem. 1996, 33, 585.

[11] Riley, T.; Stolnik, S.; Heald, C.R.; Xiong, C.D.; Garnett, M.C.; Illum,; Davis, S.S.;

Purkiss, S.C.; Barlow, R.J.; Gellert, P.R.; Langmuir 2001, 17, 3168.

[12] Lin, W.J.; Chen, Y.C.; Lin CC, Chen, C.F.; Chen, J.W.; J. Biomed. Mat. Res. Part B: Appl. Biomat. 2006, 77,188.

[13] Sutton, D.; Wang, S.; Nasongkla, N.; Gao, J.; Dormidontova, E.E.; Experimental Biology and Medicine 2007, 232, 1090.

[14] Pitt, C.G.; Langer, R.; Chasi, M.; Biodegradable Polymer as drug Delivery Systems, Eds., Marcel Dekker: New York, 1999, p 71.

[15] Sugimoto, H.; Inoue, S.; Polymerization by metalloporphyrin and related complexes, Springer-Verlag: Berlin 1999, Vol 146, pp 9-119.

[16] Kowalski, A.; Duda. A.; Penczek. S.; Macromol. Rapid. Commun. 1998, 19, 567.

[17] Kowalski, A.; Duda, A.; Penczek, S.; Macromolecules 2000, 33, 7359.

[18] Degee, O.; Dubois, P.; Jacobsen, S.; Fritz, S.G.; Jerome, R.;J.; Polym. Sci. Polym. Chem. 1999, 37, 2413.

[19] Schwach, G.; Coudane, J.; Engel, R.; Vert, M.; Polym. Bull. 1996, 37, 771.

[20] Wang, X.; Lioa, K.; Quan, D.; Wu, Q.; Macromolecules 2005, 38, 4611.

[21] Kricheldorf, H.R.; Boettcher, C.; Makromol. Chem. 1993, 194, 463.

[22] Kricheldorf, H.R.; Damrau, D.O.; Macromol. Chem. Phys. 1997, 197, 1767. 
[23] Kowalski, A.; Duda, A.; Penczek, S.; Macromol. Rapid. Commun. 1998, 19, 567.

[24] Vert, M.; Schwach, G.; Coudane, J.; Polym. Bull. 1994, 32, 617.

[25] Vert, M.; Schwach, G.; Coudane, J.; J. Macromol. Sci. Part A: Pure Appl. Chem. 1995, 32, 787.

[26] Schwach, G.; Coudane, J.; Engel, R.; Vert, M.; Polym. Int. 1998, 46, 177.

[27] Schwach, G.; Vert, M.; Int. J. Biol. Macromol. 1999, 25, 283.

[28] Schwach, G.; Coudane, J.; Engel, R.; Vert, M.; Biomaterials 2002, 23, 993.

[29] Schwach, G.; Coudane, J.; Engel, R.; Vert, M.; Polym. Bull. 1996, 37, 777.

[30] Kricheldorf, H.R.; Damru, D.O.; Macromol. Chem. Phys. 1997, 198, 1753.

[31] Kricheldorf, H.R.; Kreiser-Saunders, I.; Macromol. Chem. Phys. 1998, 199, 1081.

[32] Kricheldorf, H.R.; Damru, D.O.; Macromol. Chem. Phys. 1998, 199,1089.

[33] Dittrich, W.; Schulz, R.C.; Angew. Makromol. Chem. 1971, 15, 109.

[34] Kleine, J.; Kleine, H.; Makromol. Chem. 1959, 30, 23.

[35] Nijenhuis, A.; Grijpma, D.A.; Pennings, A.J.; Macromolecules 1992, 5, 6419.

[36] Chabot, F.; Vert, M.; Chapelle, St.; Granger, P.; Polymer 1983, 24, 43.

[37] Schwach, G.; Coudane, J.; Engel, R.; Vert, M.; Polym. Bull. 1994, 32, 617.

[38] Kreiser-Saunders, J.; Kricheldorf, H.R.; Macromol. Chem. Phys. 1998, 199, 1081.

[39] Kowalski, A.; Libizowski, J.; Majuska, K.; Duda, A.; Penczek, S.; Polymer 2007, 48, 3952.

[40] Lemmouchi, Y.; Perry, M.; Amass, A.J.; Chakraborty, K.; Schué, F.; J. Polym. Sci. Part A: Polym. Chem. 2007, 45, 2235.

[41] Piao, L.; Deng, M.; Chen, X.; Jiang, L.; Jing, X.; Polymer 2003, 44, 2331.

[42] Zhong, Z.; Dijksytra, J.; Birg, C.; Westerhausen, M.; Feijen, J.; Macromolecules 2001, 34, 3863.

[43] Kricheldorf, H.R.; Hachmann-Thiessen, H.; Schwarz, G.; BioMacromolecules 2004, 5, 492.

[44] Dobrzynski, P.; Kasperczyk, J.; Bero, M.; Macromolecules 1999, 32, 4735.

[45] Tasaka, F.; Miyazaki, H.; Ohaya, Y.; Ouchi, T.; Macromolecules 1999, 32, 6386.

[46] Kricheldorf, H.R.; Serra, A.; Polym. Bull. 1985, 14, 497.

[47] Zhong, Z.; Anconé, M.J.K.; Dijkstra, .P.P.J.; Borg, C.; Westerhoussen, M.; Feijen, J.; Polym. Bull. 2001, 46, 3863. 
[48] Yuan, M.; Liu, D.; Xiong, C.; Deng, X.; Eur. Polym. J. 1999, 35, 2139.

[49] Dunsing, R.; Kricheldorf, H.R.; Polym. Bull. 1985, 14, 491.

[50] Kricheldorf, H.R.; Lee, S.R.; Polymer 1995, 36, 2995.

[51] Wurm, B.; Keul, H.; Hocker, H.; Sylvester, G.; Leitz, E.; Ott, K.H.; Makromol. Chem. Rapid. Commun. 1993, 194, 1665.

[52] Kricheldorf, H.R.; Serra, A.0; Polym. Bull. 1985, 14, 497.

[53] Kricheldorf, H.R.; Damrau, D.O.; J. Macromol. Sci. Part A, Pure Appl. Chem. 1998, 35, 1875.

[54] Dobrzynski, P.; Kasperczyk, J.; Bero, M.; Macromolecules 1999, 32, 4735.

[55] Goeke, G.L.; Karol, F.J.; BE 860694 Union Carbide Corp., USA, Chem. Abst. 1978, 89, 164199.

[56] Rashkov, I.; Manolova, N.; Li, S.M.; Espartero, J.L.; Vert, M.; Macromolecules 1996, 29, 50.

[57] Li, S.M.; Rashkov, I. ; Espartero, J.L. ; Manolova, N. ; Vert, M. ; Macromolecules 1996, 29, 57.

[58] a) Hu, Y.; Zhang, L.; Cao, Y.; Ge, H.; Jiang, X.; Yang, C.; Biomacromolecules 2004, 5, 1756. b) Piao, L.; Dai, Z.; Deng, M.; Chen, X.; Jing, X.; Polymer 2003, 44, 2025. c) Yang, J.; Jia, L.; Yin, L.; Yu, J.; Shi, Z.; Fang, Q.; Cao, A.; Macromolecular Bioscience 2004, 4, 1092.

[59] Biela, T.; Duda, A.; Penczek, S.; Macromol. Symp 2002, 183, 1.

[60] Ge, H.X.; Hu, Y.; Yang, S.C. ; Jiang, X.Q. ; Yang, C.Z.; J. Appl. Polym. Sci. 2000, 75, 874.

[61] Lu, C.; Liu, L.; Guo, S.R.; Zhang, Y.; Li, Z.; Gu, J.; Eur. Polym. J. 2007, 43, 1857.

[62] Larue, I.; Adam, M.; da Silva, M.; Sheiko, S.S.; Rubinstein, M.; Macromolecules 2004, 37, 5002.

[63] Ouarti, N.; Viville, P.; Lazzaroni, R.; Minatti, E.; Schappacher, M.; Deffieux, A.; Langmuir 2005, 1, 9085.

[64] Park, S.Y.; Han, D.K.; Kim, S.C.; Macromolecules 2001, 34, 8821.

[65] Owens, D.K.; Wendt, R.C.; J. Appl. Sci. 1969, 13, 1741. 